\title{
Self-Esteem and Resilience in Students of Teaching: Evolution Associated with Academic Progress
}

\author{
Antonio Fernández-Castillo $\left(\mathbb{D}\right.$, Helena Chacón-López $\left(\mathbb{D}\right.$, and María J. Fernández-Prados ${ }^{\oplus}$ \\ Department of Developmental and Educational Psychology, Faculty of Educational Sciences, University of Granada, \\ Granada, Spain \\ Correspondence should be addressed to Antonio Fernández-Castillo; afcastil@ugr.es
}

Received 19 October 2021; Revised 9 November 2021; Accepted 12 November 2021; Published 19 January 2022

Academic Editor: Ehsan Namaziandost

Copyright (c) 2022 Antonio Fernández-Castillo et al. This is an open access article distributed under the Creative Commons Attribution License, which permits unrestricted use, distribution, and reproduction in any medium, provided the original work is properly cited.

\begin{abstract}
Resilience is the ability of the person to face adverse situations and emerge stronger from them. On the other hand, self-esteem is the general assessment that a person makes of himself. In the educational field, situations that can be related to both factors converge. Not too many studies have focused so far on knowing how these variables evolve during the training of future teachers. In the present study, we intend to check the levels of self-esteem and resilience in a sample of teaching students as well as to explore whether there is an association between the different levels of self-esteem and the resilience of the participants. This is a crosssectional descriptive investigation through an evaluation instrument. The sample consists of 1547 students aged 17-57 years. The sample consisted of 916 primary education students (59.2\%) and 631 early childhood education students (40.8\%). Of these, 337 were men, 1195 were women, and 14 of them did not indicate their gender. The results confirm a positive association between selfesteem and resilience. Furthermore, an increase in the levels of both variables has been found as students progress in their studies. These data verify that the students seem to be in a position to face adverse situations, as well as qualified to transfer these competencies during the performance of their future teaching work.
\end{abstract}

\section{Introduction}

Currently, higher education institutions should encourage students not only to acquire knowledge and skills but also the ability to innovate, adapt to change [1], or cope with adversity. The development of these competencies together with adequate levels of self-esteem play a fundamental role in students of teaching specialties, not only because they will provide the students with resources to overcome difficult events but also because the students will have the opportunity to apply them in their professional future.

1.1. Literature Review. The ability to cope with adverse experiences and difficult or stressful situations from a positive adaptation is called resilience [2]. In most cases, resilience allows the person to return to their previous state of mental, emotional, and cognitive activity [3]. The degree of resilience varies from one person to another, each being aware of their level [4], and it changes over time, increasing if the person has a favourable environment [5] or is trained [6]. More resilient people are considered to have greater emotional balance when facing stressful situations, better withstanding pressure, and thus preventing the negative psychological effects derived from it $[7,8]$. Positive correlations have also been found between happiness and resilience [9]. In fact, in adolescent, preuniversity students, and university students, it has been detected that high levels of resilience prevent the appearance of mental health problems $[10,11]$ are positively associated with greater life satisfaction and quality of life [12] and negatively correlated with burnout $[13,14]$.

Improving resilience depends on the individuals' coping styles or strategies and the personality factors that may 
configure them to act as mediators [15]. These mediators include self-esteem, locus of control, self-efficacy, hope, stress-coping strategies, or a sense of humour [16]. According to Prince-Embury's [17] model, the variables that constitute resilience include three general factors: (a) a sense of dominance that includes aspects such as optimism, adaptability, and self-efficacy; (b) a sense of connection that considers the perceived social support and that manifests as tolerance, comfort, support and trust; and (c) emotional reactivity, which is related to appropriate skills of emotional self-regulation, manifesting as sensitivity factors, greater or lesser weakness, and speed of recovery. Prince-Embury and Saklofske [18] found that the sense of dominance could correlate positively with resilience, whereas the sense of connection would correlate negatively.

As has been highlighted, self-esteem is one of the personality factors that can shape resilience [16]. Among other shared aspects is the ability to change over time as a result of experiences in the social environment [19]. According to Harter [20], self-esteem refers to the value that each individual attributes to their particular way of perceiving themselves, with a sense of self-worth and self-competence forming part of it [21]. For a long time, self-esteem has been linked in some studies to self-concept [22, 23].

Adequate levels of self-esteem are indicators of psychological well-being and personal satisfaction that contribute to mental balance and general health [24, 25], having important repercussions on the development of a positive life and the achievement of objectives [26]. People with high self-esteem feel more capable of carrying out any task or activity, and they are bolder to express different opinions from those of most people, as well as to share creative ideas [27]. Likewise, high self-esteem allows maintaining high levels of internal motivation and reduces external motivation [28]. It can also increase self-regulation, reduce the perception of fear or anxiety, and lead to new goals $[29,30]$. Self-esteem is also considered as an important psychological resource that buffers stress or negative events $[31,32]$ and difficulties that accumulate in university students from the beginning to the end of their studies [33,34]. Also, a positive relationship between self-esteem and students' academic performance has been demonstrated [34].

Different studies have found a positive correlation between self-esteem and resilience in the university population [3, 35-37]. Furthermore, these variables have been related to psychological alterations [38] and entrepreneurial skills in university students trained through business simulation games [6].

1.2. Current Study. Some authors, such as Ainsworth and Oldfield [39] and Mansfield et al. [40], include the relationship between resilience and self-esteem as an important element in teacher education, concluding that there is a close relationship between both, thus as their function in the development of the professional role; but not much literature has analysed in depth their relationship in teaching students, or contemplates their development throughout the academic years. This lack has motivated the present study, starting from the consideration that adequate levels of selfesteem and resilience are of great value in students who study teaching specialties, who will have the opportunity to project both competencies in their future professional practice.

Therefore, the objectives pursued in this study are as follows:

(1) To examine the levels of self-esteem and resilience in a sample of teaching students

(2) To explore whether there is a significant association between self-esteem and resilience

(3) The third objective aims to determine possible differences in self-esteem and resilience among the participants enrolled in the specialties of teaching in primary education and early childhood education

(4) Another aim is to determine a possible evolution of self-esteem and resilience associated with the academic year among newly enrolled students compared to first-, second-, third-, and fourth-year students

(5) Finally, the fifth objective proposes to analyse in more depth whether differences in resilience are observed as a function of different levels (low, medium, and high) of self-esteem in the participants

\section{Materials and Methods}

2.1. Study Design. This research is based on a descriptive cross-sectional study using a survey in a sample of students enrolled at the Faculty of Educational Sciences, University of Granada, Spain. The sample of participants was drawn through a simple and stratified random probability sampling. The variables studied were self-esteem and resilience in addition to other descriptive data of the sample under study. This methodology is considered very appropriate to achieve the proposed research objectives.

2.2. Sample. Participants in the present study were a total of 1547 students, who voluntarily completed self-reports. Among them, 916 were enrolled in the primary education teaching specialty $(59.2 \%)$ and 631 in the early childhood education specialty (40.8\%), at the Faculty of Educational Sciences of the University of Granada (Spain). The distribution by course in which they were enrolled, as well as the time when the data were collected, is detailed in Table 1.

The mean age of the participants was 20.52 years $(\mathrm{SD}=3.08)$, with an age range of $17-57$. Regarding gender, 337 (22\%) were men, 1195 (77\%) were women, and 15 (1\%) did not report this information.

2.3. Instruments. In addition to the questionnaires listed below, sociodemographic data were collected from the participants regarding the teaching specialty in which they were enrolled, the course they were in, age and gender.

The Spanish version [41] of the Rosenberg Self-Esteem Scale [42] was used to determine the levels of self-esteem in the 
TABLE 1: Descriptive analysis of the course in which the participants were enrolled and time of evaluation.

\begin{tabular}{lcc}
\hline Course/evaluation time & Frequency & Percentage \\
\hline First course: newly entered & 400 & 25.9 \\
First course: end of course & 358 & 23.1 \\
Second course: end of course & 334 & 21.6 \\
Third course: end of course & 305 & 19.7 \\
Fourth course: end of course & 150 & 9.7 \\
Total & 1547 & 100.0 \\
\hline
\end{tabular}

participants. It is a world-renowned self-report instrument with excellent psychometric properties. It is structured in 10 items that are answered on a four-point scale ranging from 1 (strongly disagree) to 4 (strongly agree). The sum of the scores of each item provides the person's self-esteem score, taking into account that the higher the score, the more the self-esteem. Half of the items are expressed negatively, so their scores must be reversed to obtain the general score, which can range between 10 and 40. The scale has three levels of self-esteem [42]: "low self-esteem," which includes scores equal to or below 25; "average self-esteem," scores between 26 and 29; and "high selfesteem," for scores equal to or greater than 30 . The scale has obtained quite good internal consistency indices in many studies. For example, Robins et al. [43] found a Cronbach alpha between 0.88 and 0.90 . In the Spanish version, the scale also has excellent psychometric properties, as evidenced by an alpha of 0.87 or also the excellent test-retest reliability [41]. In the present study, the Cronbach alpha obtained was 0.83 .

To assess resilience in the sample of participants, the 30item Subjective Resilience Questionnaire [44] was used. The questionnaire assesses the degree of general resilience and differentiates three specific factors, corresponding to the students' degree of resilience to adverse situations in their relationships with teachers, peers, and family. Responses are made on a five-point format ranging from 1 (strongly disagree) to 5 (strongly agree). Half of the items are expressed negatively, so the corresponding scores must be reversed to operate with them. The total sum of the scores represents the individual's general resilience, ranging from a minimum of 30 points to a maximum of 150 . The psychometric properties of the instrument have been widely verified. For example, its authors report an alpha of 0.85 in the validation study [44]. Other studies have found a Cronbach alpha of 0.85 for the general scale, $\alpha=0.74$ for the Faculty subscale, $\alpha=0.64$ for the Peer subscale, and $\alpha=0.65$ for the Family subscale [45]. More recently, Villasana, Alonso-Tapia, and Ruiz [15] reported even higher values, with a consistency index of 0.97 for the General scale, 0.98 for the Faculty scale, 0.93 for the Peer subscale, and 0.93 for the Family subscale. In the present study, the internal consistency value of the General scale was $\alpha=0.91$.

The assessment instruments have been validated in the Spanish population and extensively used in psychological studies in our country. In the current research, we have relied on these results, and apart from reliability analyses in our sample, no additional analyses have been carried out on their psychometric properties and validity. The original data and statistics can be consulted in the incorporated bibliographic references.
2.4. Procedure. To collect the data, the researchers visited various classrooms of the Faculty of Educational Sciences of the University of Granada (Spain), both in the teaching specialties of primary education and early childhood education.

Permission was previously requested from the professors of the different courses and subjects to briefly use their classrooms and allow the researchers' attendance. The students were then asked to complete self-reports. Beforehand, they were informed that participation was voluntary and anonymous, because at no time during the participation would personal data that could identify them be collected. They were briefly informed of the objectives of the investigation, and that they could leave the study at any time if they wished.

After collecting the questionnaires, the data were entered into a database designed for further use in statistical analyses. Regarding the specific evaluation instruments, the instructions offered by the authors were followed for handling the data, reversing the scores in some items, scaling, criteria for completing and extracting general scores, etc.

2.5. Data Analysis. The data were analysed with the SPSS statistical program version 24 , and the analyses included descriptive and frequency analyses, Pearson's bivariate correlations, analysis of mean differences (generally, ANOVA of one factor or similar) with posthoc tests of comparisons based on the minimum significant difference test (hereinafter MSD), among others. In all the tests, the assumed statistical significance level was 0.05 .

\section{Results}

First, self-esteem and resilience levels were examined in the sample of teaching students (first established objective), the results of which showed a self-esteem mean of $M=31.40$ $(\mathrm{SD}=4.58), \quad$ median $=31$; and for resilience, $M=99.78$ $(\mathrm{SD}=16.64)$, median $=99$.

The levels of self-esteem that can be established, according to the scoring of the Rosenberg scale [42], are shown in Table 2. As can be seen, most of the participants (66.5\%) had a high level of self-esteem.

Next, to explore a possible association between self-esteem and resilience, Pearson bivariate correlation analysis was carried out, obtaining a value of $r=0.374(p=0.00)$. Therefore, higher levels of self-esteem are significantly associated with higher levels of resilience in the participants.

Third, possible differences in self-esteem and resilience were found between the participants enrolled in the primary and early childhood education specialties, through two analyses of variance. The mean of self-esteem in the primary education participants was $M=31.30 \quad(\mathrm{SD}=4.67)$ and $M=31.54(\mathrm{SD}=4.44)$ in early childhood education, respectively, with no significant differences between the two groups, $F(1,1544)=0.991, p=0.32$.

Regarding resilience, the mean of the primary education participants was $M=100.10(\mathrm{SD}=17.30)$, and that of the early childhood education reached the value of $M=99.32$ 
TABLE 2: Descriptive results according to levels of self-esteem.

\begin{tabular}{lcc}
\hline & Frequencies & Percentage \\
\hline Low self-esteem & 157 & 10.1 \\
Medium self-esteem & 361 & 23.3 \\
High self-esteem & 1028 & 66.5 \\
Total & 1546 & 99.9 \\
Missing & 1 & 0.1 \\
Total & 1547 & 100 \\
\hline
\end{tabular}

$(S D=15.64)$. The difference between the two means was nonsignificant, $F(1,1545)=0.823, p=0.36$, so it is concluded that there is no difference in resilience between the two groups of students.

In order to explore possible differences associated with the academic year in self-esteem and resilience among newly enrolled students compared to students in the final year, and in the first, second, third, and fourth year (fourth objective), two comparative analyses of means with post hoc tests were performed. Both in the case of self-esteem, $F(4,1542)=$ $5.302, p<0.00$, and in that of resilience, $F(4.1542)=6.026$, $p<0.00$, the analysis of variance showed significant results indicating that the levels of both variables increased throughout the career (see Figures 1 and 2). Detailed descriptive results, as well as partial comparisons of the minimum significant difference test (MSD) of the group means, are detailed in Tables 3 and 4 .

It should be noted that, although in both variables, the tendency to increase throughout the course is clear, the MSD tests indicated a stabilization from the second year on in the case of self-esteem.

Finally, we investigated in more detail possible differences in resilience based on the participants' level (low, medium, and high) of self-esteem. For this purpose, a comparison of means was performed, again with a post hoc MSD test. The results indicated an increase in resilience at higher levels of self-esteem, $F(2,1543)=76.83, p<0.00$, as illustrated in Figure 3.

Descriptive results are presented in Table 5, as well as partial MSD means of the group comparisons.

\section{Discussion}

The first objective of this research was to determine the levels of self-esteem and resilience presented by a sample of teaching students at the University of Granada. The results revealed that a high percentage of the students $(66.5 \%)$ had high self-esteem and $23.3 \%$ had medium self-esteem. This result is consistent, given the high scores obtained in resilience (median of 99 points) and the positive correlation between the two variables (second objective of the study), which indicates that higher levels of self-esteem are associated with higher scores on resilience. This result coincides with previous studies such as that of Olsson et al. [16], who considered self-esteem as one of the factors that contribute to resilience, and with the findings of other works carried out in the university population [3, 35-37].
On another hand, no differences in self-esteem and resilience were detected between the students enrolled in the primary and early childhood specialties (third objective), suggesting that the students from both degrees did not differ in these variables.

With regard to the fourth objective, an increase in selfesteem and resilience scores was detected in newcomers to the fourth grade. However, although in both variables, the tendency to increase throughout the studies is clear, the MSD tests indicated a stabilization as of the second year in the case of selfesteem. Specifically, the increase occurs from the time students enter until the end of the second year, and it decreases slightly from this moment until the end of the third course, and from there, it rises again. Although there is an increase in self-esteem (increasing from 30.57 points at the beginning to 32.04 at the end), there seems to be some stabilization from the second year to the third. However, this last aspect is descriptive and could become the objective of research in greater depth in future studies. In any case, this observed increase is consistent with the findings of Coll [19], reporting that self-esteem evolves over the years as a result of the person's experience in their social environment and their perception of greater self-worth and self-competence [21], associated with the achievement of objectives [26]. The maturity acquired during this period and the feeling of independence could have contributed to the increase in levels of self-esteem, providing the students with more resources to resolve new situations.

As can be seen, the developmental pattern is quite clear in the increase in resilience throughout the career (increasing from 97.71 points at entry to 103.9 at the end of the career), and this trend is linear and significant. Therefore, this variable follows an ascending pattern throughout the courses, leading us to suspect that the experience or sense of dominance experienced by the students throughout their stay at the university will provide them with the means to develop a greater ability to cope with adverse elements. This result is in line with the proposal of Prince-Embury and Saklofske [17], who detected that the sense of dominance could positively correlate with resilience.

Finally, the results of the present study show a clear increase in resilience as the levels of self-esteem increase in the participants of teaching specialties, coinciding with the findings of other investigations [16, 36, 37]. As other studies have highlighted, people with high self-esteem feel more capable of carrying out any task or activity are bolder about expressing opinions that differ from those of most people, and they share creative ideas more easily [27]. They also self-regulate better, show less fear or anxiety, and are more inclined to seek new goals $[29,30]$. The levels of self-esteem shown by the teaching students who participated in this research may have acted as a psychological buffer against negative events [31, 32], allowing them to cope with these events as they progressed through their training. This is encouraging for this population, considering that previous works have shown that university students' difficulties increase from the beginning to the end of their studies $[33,34]$. 


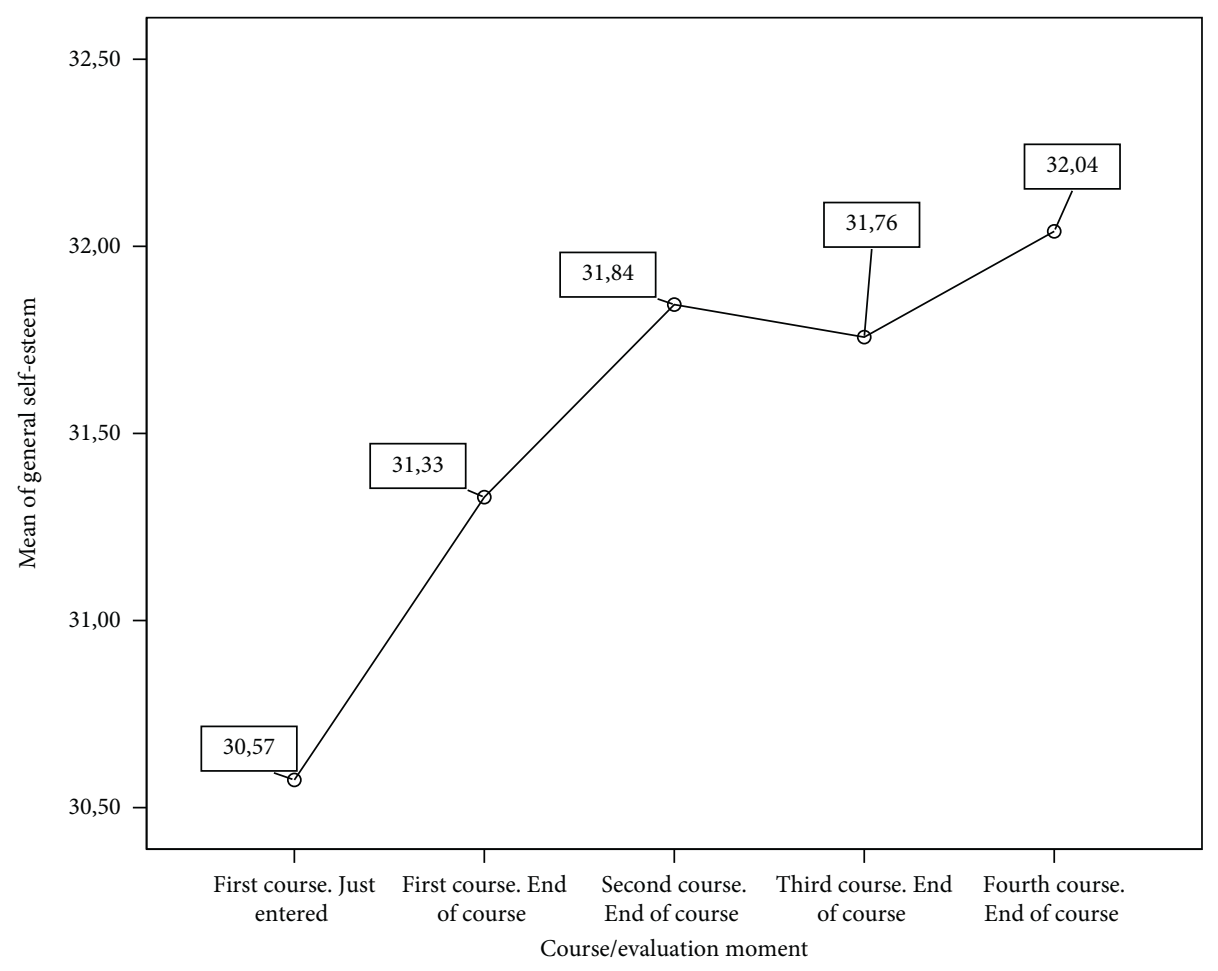

FIgURE 1: Developmental pattern of self-esteem in teaching students.

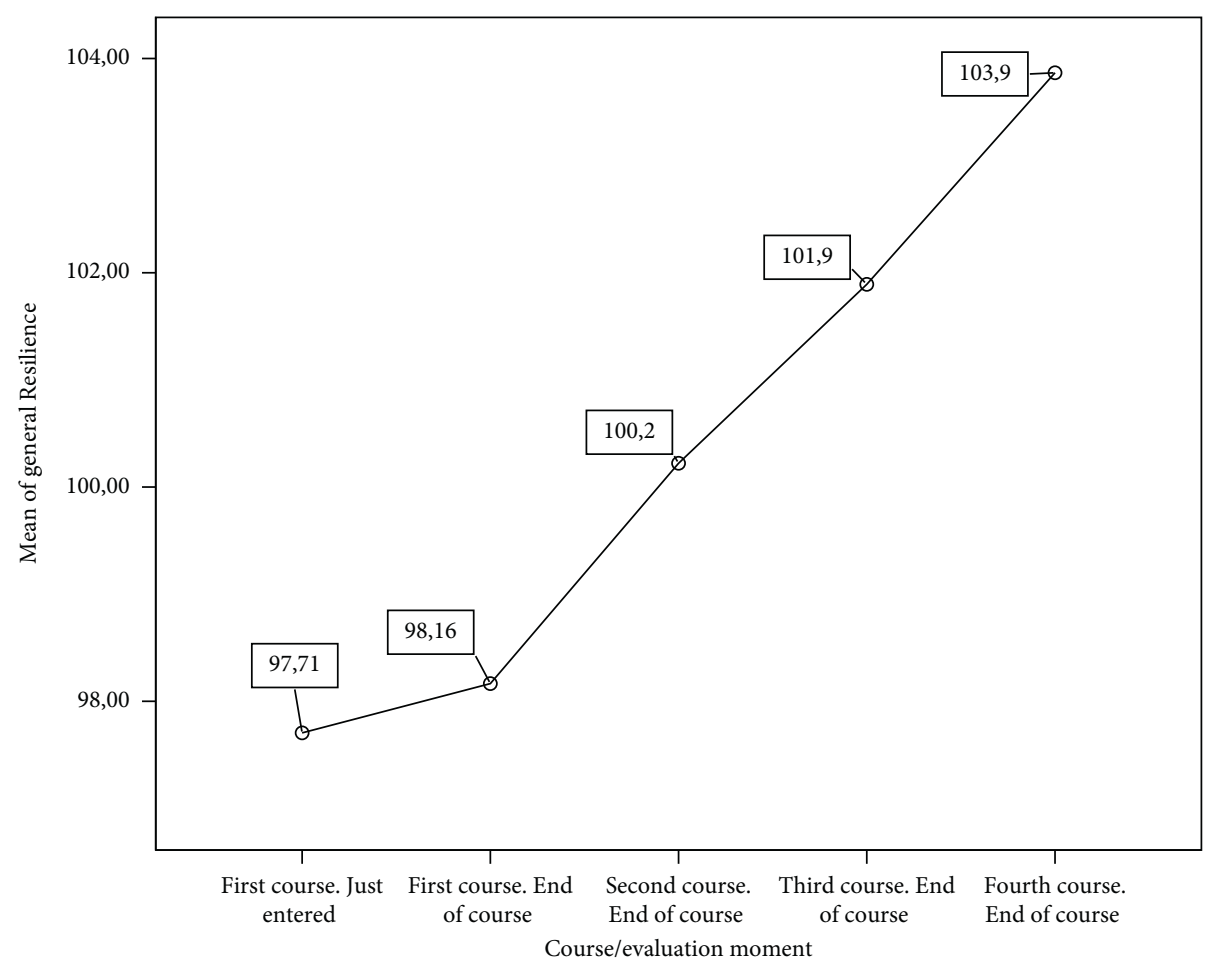

FIGURE 2: Developmental pattern of resilience in teaching students. 
TABLE 3: Descriptive and post hoc tests (MSD) of differences in self-esteem according to the academic course.

\begin{tabular}{|c|c|c|c|}
\hline \multicolumn{4}{|c|}{ Self-esteem } \\
\hline (I) Course/evaluation moment & (J) Course/evaluation moment & Mean differences (I-J) & Sig. \\
\hline $\begin{array}{l}\text { First course: newly entered } \\
M=30.57, \mathrm{SD}=4.64\end{array}$ & $\begin{array}{c}\text { First course: end of course } \\
\quad M=31.33, \mathrm{SD}=4.35\end{array}$ & $-0.76^{*}$ & 0.02 \\
\hline First course: newly entered & $\begin{array}{c}\text { Second course: end of course } \\
M=31.84, \mathrm{SD}=4.49 .25\end{array}$ & $-1.27^{*}$ & 0.00 \\
\hline First course: newly entered & $\begin{array}{l}\text { Third course: end of course } \\
\qquad M=31.76, \mathrm{SD}=4.67\end{array}$ & $-1.18^{*}$ & 0.00 \\
\hline First course: newly entered & $\begin{array}{l}\text { Fourth course: end of course } \\
\qquad M=32.04, \mathrm{SD}=4.73\end{array}$ & $-1.47^{*}$ & 0.00 \\
\hline First course: end of course & Second course: end of course & -0.52 & 0.14 \\
\hline First course: end of course & Third course: end of course & -0.43 & 0.23 \\
\hline First course: end of course & Fourth course: end of course & -0.71 & 0.11 \\
\hline Second course: end of course & Third course: end of course & 0.09 & 0.81 \\
\hline Second course: end of course & Fourth course: end of course & -0.20 & 0.66 \\
\hline Third course: end of course & Fourth course: end of course & -0.28 & 0.53 \\
\hline
\end{tabular}

*The difference between the means is significant at the 0.05 level.

TABle 4: Descriptive and post hoc tests (MSD) of differences in resilience according to the considered academic groups.

\begin{tabular}{|c|c|c|c|}
\hline \multicolumn{4}{|c|}{ Resilience } \\
\hline (I) Course/evaluation moment & (J) Course/evaluation moment & Mean differences (I-J) & Sig. \\
\hline $\begin{array}{l}\text { First course: just entered } \\
M=97.71, \mathrm{SD}=15.49\end{array}$ & $\begin{array}{c}\text { First course: end of course } \\
M=98.16, \mathrm{SD}=16.39\end{array}$ & -0.46 & 0.70 \\
\hline First course: just entered & $\begin{array}{c}\text { Second course: end of course } \\
\qquad M=100.22, \mathrm{SD}=17.25\end{array}$ & $-2.52^{*}$ & 0.04 \\
\hline First course: just entered & $\begin{array}{c}\text { Third course: end of course } \\
\qquad M=101.89, \mathrm{SD}=17.56\end{array}$ & $-4.19^{*}$ & 0.00 \\
\hline First course: just entered & $\begin{array}{c}\text { Fourth course: end of course } \\
\qquad M=103.87, \mathrm{SD}=15.75\end{array}$ & $-6.16^{*}$ & 0.00 \\
\hline First course: end of course & Second course: end of course & -2.06 & 0.10 \\
\hline First course: end of course & Third course: end of course & $-3.73^{*}$ & 0.00 \\
\hline First course: end of course & Fourth course: end of course & $-5.70^{*}$ & 0.00 \\
\hline Second course: end of course & Third course: end of course & -1.67 & 0.20 \\
\hline Second course: end of course & Fourth course: end of course & $-3.65^{*}$ & 0.03 \\
\hline Third course: end of course & Fourth course: end of course & -1.98 & 0.23 \\
\hline
\end{tabular}

${ }^{*}$ The difference between the means is significant at the 0.05 level.

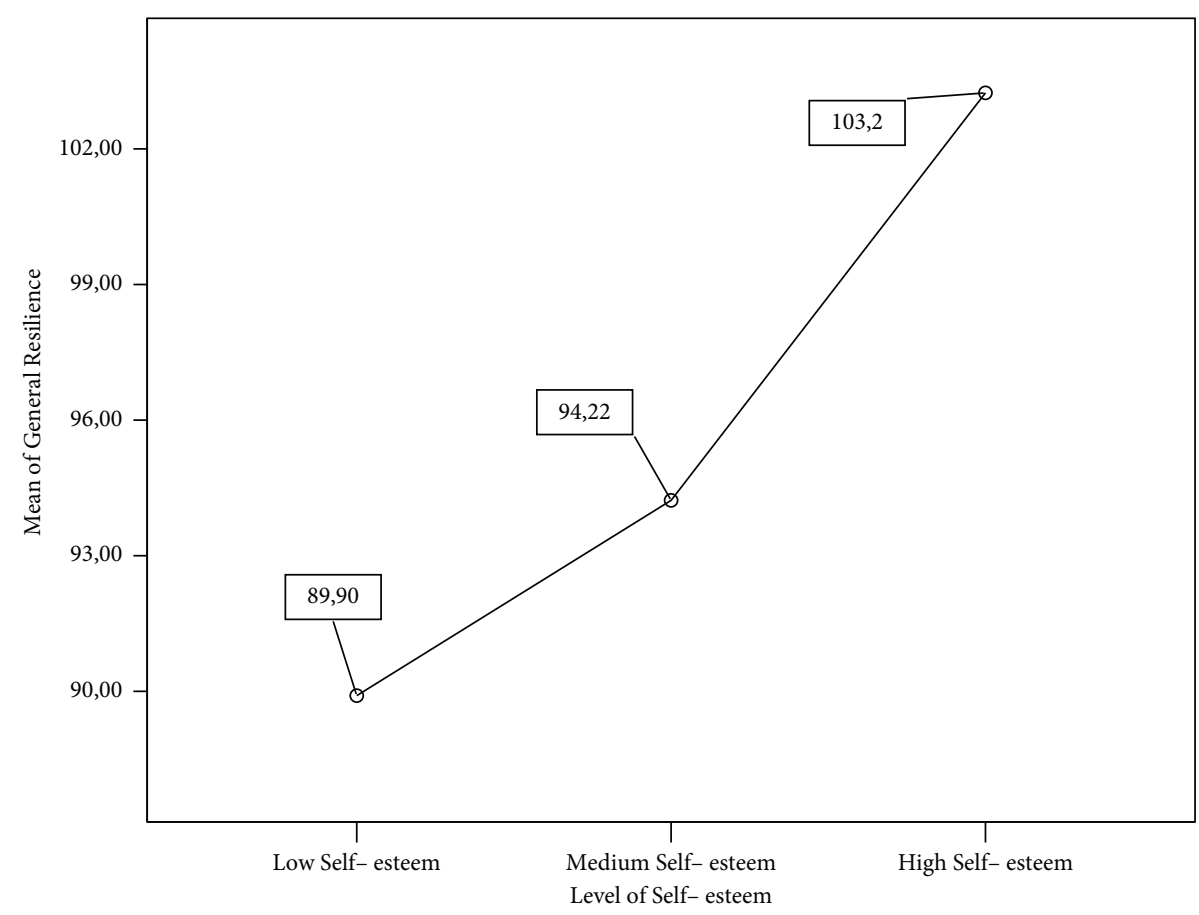

FIgURE 3: Differences in resilience according to self-esteem levels. 
TABLE 5: Descriptive and post hoc tests (MSD) of differences in resilience according to self-esteem levels.

\begin{tabular}{lccc}
\hline & \multicolumn{2}{c}{ Resilience } & \\
(I) Self-esteem level & (J) Self-esteem level & Mean differences (I-J) & Sig. \\
\hline Low self-esteem & Medium self-esteem & $-4.32^{*}$ & 0.00 \\
$M=89.90, \mathrm{SD}=15.23$ & $M=94.22, \mathrm{SD}=14.42$ & $-13.33^{*}$ & 0.00 \\
Low self-esteem & High self-esteem & $-9.01^{*}$ & 0.00 \\
Medium self-esteem & $M=103.24, \mathrm{SD}=16.46$ & High self-esteem & \\
\hline
\end{tabular}

*The difference between the means is significant at the 0.05 level.

\section{Conclusions}

The results of the study are encouraging for the university population studying education degrees, showing that a high percentage of the participants obtained good scores in selfesteem and resilience and variables of considerable value for success in studies and for future practice. It also finds (coinciding with the results found in other research) that higher levels of self-esteem are associated with higher scores in resilience, both in the primary and early childhood education specialty students, and there is a significant improvement in self-esteem and resilience scores (even more so in this variable) in students as they progress in their studies. It seems that the stay at the University, the experiences, and the training received during these four years have had a positive influence on their self-esteem and, mainly, on their ability to face adverse, difficult, or stressful situations with a positive adaptation.

\subsection{Limitations of Present Study and Suggestions for Future} Studies. One of the weaknesses of this study is related to the sample. Although it can be considered that the number of participants is sufficient, given the difficulty of working with samples matched by gender, the representativeness could be improved. This is a challenge that could be addressed in future studies. Regarding the type of statistical analysis carried out, it should be noted that the results obtained do not allow conclusions to be drawn about causality, but a relationship between the variables analysed can be detected. Therefore, it would be interesting to continue delving into the issues analysed, attempting to match the samples, a goal that is difficult to achieve given that education degrees are chosen mostly by women.

Despite the good results obtained in the analyses carried out, it remains to be seen whether they could be attributed to other variables not contemplated in the study, such as the emotional state or academic performance of the participants throughout the studies. Therefore, we suggest taking them into account in future studies.

5.2. Implications of Present Study. Regarding the contributions of the study, in the first place, it is verified that the students of the specialties of early childhood and primary education seem to be in a position to face adverse situations from a positive perspective, taking into account their scores on two psychological factors (self-esteem and resilience) that mediate this process.
Likewise, self-esteem and resilience seem to increase as the academic path progresses. Possibly, maturation and experience throughout the career contribute to personal psychological strengthening. These results are of special interest, as these students are future education professionals, who will not only need these resources for their job performance but also because of the opportunity to transmit these strengths to the future students they work with.

\section{Data Availability}

The data and materials are available from the corresponding author upon request.

\section{Conflicts of Interest}

The authors declare that there are no conflicts of interest regarding the publication of this study.

\section{References}

[1] N. Nordin and M. Malik, "Undergraduates' barriers to creative thought and innovative in a new millennial era," Procedia-Social and Behavioral Sciences, vol. 201, pp. 93-101, 2015.

[2] A. J. Zautra, "Resilience: one part recovery, two parts sustainability," Journal of Personality, vol. 77, no. 6, pp. 1935-1943, 2009.

[3] M. Borji, N. Memaryan, Z. Khorrami, E. Farshadnia, and M. Sadighpour, "Spiritual health and resilience among university students: the mediating role of self-esteem," Pastoral Psychology, vol. 69, no. 1, pp. 1-10, 2020.

[4] M. Villasana, J. Alonso-Tapia, and M. Ruiz, "A model for assessing coping and its relation to resilience in adolescence from the perspective of 'person-situation interaction'," Personality and Individual Differences, vol. 98, pp. 205-256, 2016.

[5] S. L. Harter, "Psychological adjustment of adult children of alcoholics: a review of the recent empirical literature," Clinical Psychology Review, vol. 20, no. 3, pp. 311-337, 2000.

[6] K. Prihadi, D. Z. Y. Cheow, J. H. E. Yong, and M. Sundrasagran, "Improving resilience and self-esteem among university students with entrepreneurship simulation board game," International Journal of Evaluation and Research in Education, vol. 7, no. 1, pp. 48-56, 2018.

[7] M. Pinquart, "Moderating effect of dispositional resilience on association between hassles and psychological distress," Journal of Applied Developmental Psychology, vol. 30, no. 1, pp. 1-8, 2009.

[8] S. M. Southwick, G. A. Bonanno, A. S. Masten, C. PanterBrick, and R. Yehuda, "Resilience definitions, theory, and 
challenges: interdisciplinary perspectives," European Journal of Psychotraumatology, vol. 5, no. 1, pp. 1-14, 2014.

[9] C. A. Short, S. Barnes, J. F. Carson, and I. Platt, "Happiness as a predictor of resilience in students at a further education college," Journal of Further and Higher Education, vol. 44, no. 2, pp. 170-184, 2020.

[10] M. T. Hartley, "Examining the relationships between resilience, mental health, and academic persistence in undergraduate college students," Journal of American College Health, vol. 59, no. 7, pp. 596-604, 2011.

[11] J. Shi, Z. Chen, F. Yin, J. Zhao, X. Zhao, and Y. Yao, "Resilience as moderator of the relationship between leftbehind experience and mental health of Chinese adolescents," International Journal of Social Psychiatry, vol. 62, no. 4, pp. 386-393, 2016.

[12] L. W. Plexico, S. Erath, H. Shores, and E. Burrus, "Self-acceptance, resilience, coping and satisfaction of life in people who stutter," Journal of Fluency Disorders, vol. 59, pp. 52-63, 2018.

[13] M. Janatolmakan, Y. Torabi, S. Rezaeian, B. Andayeshgar, A. Dabiry, and A. Khatony, "The relationship between resilience and academic burnout among nursing and midwifery students in Kermanshah, Iran," Educational Research International, vol. 2021, Article ID 6647012, 7 pages, 2021.

[14] A. Fernández-Castillo and M. J. Fernández-Prados, "Resilience and burnout in educational science university students: developmental analysis according to progression in the career," Current Psychology, pp. 1-10, 2021.

[15] M. Villasana, J. Alonso-Tapia, and M. Ruiz, "Coping processes and personality factors as predictors of resilience in adolescent students: validation of a structural model," Revista de Psicodidáctica, vol. 22, no. 2, pp. 93-101, 2017.

[16] C. A. Olsson, L. Bond, J. M. Burns, D. A. Vella-Brodrick, and S. M. Sawyer, "Adolescent resilience: a concept analysis," Journal of Adolescence, vol. 26, no. 1, pp. 1-11, 2003.

[17] S. Prince-Embury, Resiliency Scales Manual for Children and Adolescents: A Profile of Personal Strengths, Harcourt Assessment, San Antonio, TX, USA, 2007.

[18] S. Prince-Embury and D. H. Saklofske, Resilience Interventions for Youth in Diverse Populations, Springer, New York, NY, USA, 2014.

[19] C. Coll, "Constructivismo y educación," in Desarrollo Psicológico Y Educación, C. Coll, J. Palacios, and A. Marchesi, Eds., Vol. 2, Psicología de la Educación Escolar, Alianza Editorial, Madrid, Spain, 2002.

[20] S. L. Harter, The Construction of Self: A Developmental Perspective, Guilford Press, New York, NY, USA, 1999.

[21] R. W. Tafarodi and W. B. Swann, "Two-dimensional selfesteem: theory and measurement," Personality and Individual Differences, vol. 31, no. 5, pp. 653-673, 2001.

[22] M. Garaigordobil and E. Bernarás, "Self-concept, self-esteem, personality traits and psychopathological symptoms in adolescents with and without visual impairment," Spanish Journal of Psychology, vol. 12, no. 1, pp. 149-160, 2009.

[23] F. Garcia and G. Musitu, AF5-Autoconocepto Forma 5. Manual, TEA Ediciones, Madrid, Spain, 4th edition, 2014.

[24] M. C. Fuentes, J. F. García, E. Gracia, and M. Lila, "Autoconcepto y ajuste psicosocial en la adolescencia," Psicothema, vol. 23, no. 1, pp. 7-12, 2011.

[25] E. Goñi, I. Esnaola, A. Rodríguez, and I. Camino, "Personal self-concept and satisfaction with life in adolescence, youth and adulthood," Psicothema, vol. 27, no. 1, pp. 52-58, 2015.

[26] S. Halder and P. Datta, "An exploration into self concept: a comparative analysis between the adolescents who are sighted and blind in India," British Journal of Visual Impairment, vol. 30, no. 1, pp. 31-41, 2012.

[27] S. M. B. Thatcher and S. A. Brown, "Individual creativity in teams: the importance of communication media mix," Decision Support Systems, vol. 49, no. 3, pp. 290-300, 2010.

[28] T. M. Amabile and J. Pillemer, "Perspectives on the social psychology of creativity," Journal of Creative Behavior, vol. 46, no. 1, pp. 3-15, 2012.

[29] C. S. Carver, M. F. Scheier, and D. Fulford, "Self-regulatory processes, stress, and coping," in Handbook of Personality: Theory and Research, O. P. John, R. W. Robins, and L. A. Pervin, Eds., Guilford Press, New York, NY, USA, 3rd edition, 2008.

[30] Y. Wang and L. Wang, "Self-construal and creativity: the moderator effect of self-esteem," Personality and Individual Differences, vol. 99, pp. 184-189, 2016.

[31] R. F. Baumeister, J. D. Campbell, J. I. Krueger, and K. D. Vohs, "Does high self-esteem cause better performance, interpersonal success, happiness, or healthier lifestyles?" Psychological Science in the Public Interest, vol. 4, no. 1, pp. 1-44, 2003.

[32] A. D. Cast and P. J. Burke, "A theory of self-esteem," Social Forces, vol. 80, no. 3, pp. 1041-1068, 2002.

[33] H. Elias, W. S. Ping, and M. C. Abdullah, "Stress and academic achievement among undergraduate students in universiti putra Malaysia," Procedia-Social and Behavioral Sciences, vol. 29, pp. 646-655, 2011.

[34] Z. Szabo, M. Marian, and M. Marian, "Stressors and reactions to stress: a cross-cultural case study in two educational programs," Journal of Evidence-Based Psychotherapies, vol. 17, no. 1, pp. 89-103, 2017.

[35] A. Haktanir, J. C. Watson, H. Ermis-Demirtas et al., "Resilience, academic self-concept, and college adjustment among first-year students," Journal of College Student Retention: Research, Theory \& Practice, vol. 17, no. 2, pp. 186-203, 2018.

[36] M. L. Martínez-Marti and W. Ruch, "Character strengths predict resilience over and above positive affect, self-efficacy, optimism, social support, self-esteem and life satisfaction," The Journal of Positive Psychology, vol. 12, no. 2, pp. 110-119, 2017.

[37] Z. Tras, C. Arslan, and E. Hamarta, "An examination resiliency in university students in terms of self-esteem and social self-efficacy," International Journal of Academic Research, vol. 5, no. 3, pp. 323-328, 2013.

[38] Y. Liu, Z. Wang, C. Zhou, and T. Li, "Affect and self-esteem as mediators between trait resilience and psychological adjustment," Personality and Individual Differences, vol. 66, pp. 92-97, 2014.

[39] S. Ainsworth and J. Oldfield, "Quantifying teacher resilience: context matters," Teaching and Teacher Education, vol. 82, pp. $117-128,2019$.

[40] C. F. Mansfield, S. Beltman, T. Broadley, and N. WeatherbyFell, "Building resilience in teacher education: an evidenced informed framework," Teaching and Teacher Education, vol. 54, pp. 77-87, 2016.

[41] R. Vázquez-Morejón Jiménez, R. Jiménez García-Bóveda, and A. J. Vázquez Morejón, "Escala de autoestima de Rosenberg: fiabilidad y validez en población clínica española," Apuntes de Psicología, vol. 22, no. 2, pp. 247-255, 2004.

[42] M. Rosenberg, Society and the Adolescent Self-Image, Princeton University Press, Princeton, NJ, USA, 1965.

[43] R. W. Robins, H. M. Hendin, and K. H. Trzesniewski, "Measuring global self-esteem: construct validation of a single-item measure and the rosenberg self-esteem scale," 
Personality and Social Psychology Bulletin, vol. 27, no. 2, pp. 151-161, 2001.

[44] J. Alonso-Tapia, C. Nieto, and M. A. Ruíz, "Measuring subjective resilience despite adversity due to family, peers and teachers," Spanish Journal of Psychology, vol. 16, pp. 1-13, 2013.

[45] J. Alonso-Tapia and M. Villasana, "Assessment of subjective resilience: cross-cultural validity and educational implications/Evaluación de la resiliencia subjetiva: validez transcultural e implicaciones educativas del 'Cuestionario de Resiliencia Subjetiva' (SRQ)," Infancia Y Aprendizaje, vol. 37, no. 3, pp. 629-664, 2014. 